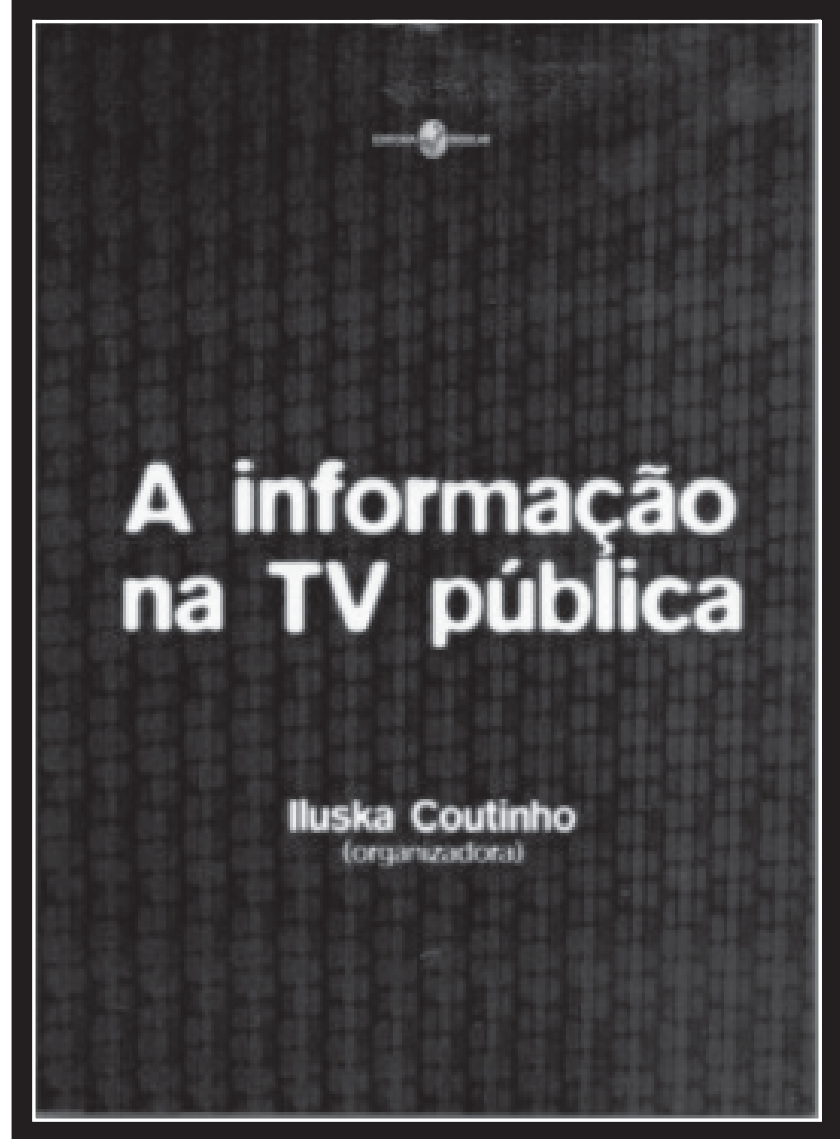

COUTINHO, Iluska (org.). A informação na TV pública. Florianópolis: Insular, 2013. 320 p. 


\section{TV pública sob o olhar do pesquisador}

Public TV in the perspective of the researcher

\section{Cristiane Garcia Grande*}

A televisão no Brasil é uma mídia de elevada inserção social que atua como substituta cultural e fonte de informação de grande parte da população. Neste contexto, o telejornal, responsável por levar a notícia aos brasileiros, presta um serviço público ao realizar a cobertura dos principais acontecimentos no país e no mundo, com a credibilidade de profissionais experientes no telejornalismo nacional. Uma responsabilidade maior recai sobre a emissora pública, destinada a produzir informação com liberdade editorial, ou seja, desvinculada do poder executivo que a financia.

Em A informação na TV pública, a organizadora Iluska Coutinho imprime seu conhecimento e experiência para avaliar, com um grupo de pesquisadores da Universidade Federal de Juiz de Fora (UFJF), o telejornalismo e a informação na TV pública, em especial na TV Brasil, como também na TV Cultura e no RTP2, sendo este último um canal de Rádio e Televisão de Portugal.

A gênese desta obra, iniciada em 2010, surgiu da interlocução entre o Conselho Curador da Empresa Brasil de Comunicação (EBC), gestora do canal TV Brasil, e a academia, resultando em parcerias com universidades públicas para a avaliação da produção da TV Brasil. Postura esta que merece destaque, sendo que a EBC foi criada em 2007 para fortalecer o sistema público de comunicação e conta com a participação da sociedade civil no controle de sua gestão e programação, por meio da atuação do Conselho Curador.

Com esta iniciativa, o grupo de pesquisa Jornalismo, Imagens e Representação, liderado por Iluska Coutinho, iniciou a pesquisa que

* Graduada em Comunicação Social - habilitação Jornalismo pela Universidade Estadual de Londrina e mestranda em Comunicação pela mesma instituição. 
expandiu posteriormente para outras TVs, o que possibilitou ampliar os olhares para diversas realidades no quesito emissora pública.

O livro, dividido em três partes, apresenta primeiramente um texto introdutório denominado Sobre o (Tele) Jornalismo Público: conceitos e métodos de análise, no qual Iluska Coutinho situa o leitor sobre os desdobramentos que ele vai encontrar no livro, a metodologia e os conceitos utilizados na pesquisa.

No segundo capítulo, Os telejornais públicos em avaliação, o conteúdo versa sobre os temas - Repórter Brasil: informação pública em dois tempos e (Jornal) Visual: a promessa da informação audiovisual visível para todos, de Iluska Coutinho; Diálogos no Repórter Brasil, de Allana Meirelles e Roberta Braga; "Outro olhar”: (re-) circulação midiática, participação popular e dramaturgia na TV Brasil, de Jhonatan Mata; e Jornal da Cultura, herdeiro da Hora da Notícia?, de Allana Meirelles e Jemima Bispo.

Na última parte, um material mais denso, são apresentadas as seguintes pesquisas: Caminhos da Reportagem: a informação em profundidade na TV Brasil de Roberta Braga; Opinião e informação na TV Brasil: uma avaliação dos conteúdos de 3 a 1 e Brasilianas.org de Allan Gouvêa; Pluralidade, cidadania e direito à informação: as potencialidades da democratização da comunicação a partir do programa Rede Jovem de Cidadania de Bárbara Garrido de Paiva Schlaucher; Paratodos: um caminho de diversidade e cultura para o telejornalismo brasileiro de Nara Oliveira Salles; Papo de mãe: dramas cotidianos e femininos na tela de Renata Vargas; Telejornalismo esportivo na TV Brasil: os programas No Mundo da Bolsa e Stadium de Angelo Tosta e Iluska Coutinho; Observatório da Imprensa: lugar de ler e ver notícias por dentro de Caio Cardoso de Queiroz, Rebeca Trece e Iluska Coutinho; O público: discussões no ar via programa da Ouvidoria da EBC de Raul Mourão; Pitching: a produção independente da TV Brasil de Lara Linhalis Guimarães; Edna de Mello Silva e Gizeli C. Bertollo Menezes; e A diversidade na RTP2: um estudo sobre os programas Biosfera e Sociedade Civil de Gabriela Borges. 
Se, em tese, toda televisão é pública, uma vez que os sinais de televisão trafegam pelo espectro eletromagnético controlado pelo Estado, "não existiria canal eminentemente privado" (COUTINHO, 2013, p.21), pois as TVs privadas recebem a concessão mediante o cumprimento de determinações legais e constitucionais. Deste modo, a organizadora foca as reflexões no aspecto plural de uma emissora pública de televisão, com ensejo na possibilidade de exercício do direito à comunicação.

As exigências de isenção, equilíbrio, apartidarismo e pluralidade, tão caras ao (Tele) Jornalismo e suas promessas ao cidadão também são devidas pelas emissoras de televisão, concessionárias de um serviço público, apesar da aparente dissonância com as percepções acerca de sua programação (COUTINHO, 2013, p.21-22).

Todavia, ao abranger as emissoras públicas no Brasil, que deveriam garantir não apenas a informação, mas a comunicação à sociedade, no sentido de atribuir uma representação maior dos cidadãos, induz à compreensão das distintas formas de constituição de cada uma delas. Das TVs educativas às emissoras estatais, é possível diferenciá-las segundo seus princípios, e, sobretudo, por meio de seus vínculos financeiros, editorias e da identidade construída e consolidada na sociedade.

A ideia partilhada no livro associa ainda o entendimento do exercício da comunicação com outros direitos fundamentais e "pressupõe que os cidadãos tenham voz, que essa possa ser expressa, publicizada, também na mídia" (COUTINHO, 2013, p.25).

Assim, são citados outros estudiosos evidenciadores da perspectiva de um telejornalismo mais dialógico, legitimador do direito social à comunicação, por meio da colaboração de diferentes vozes que produzem discursos, novas imagens e sons. Os principais autores visitados são Beatriz Becker e Itania Maria Mota Gomes, inspiradoras na definição teóricometodológica com ênfase na qualidade; Dominique Wolton, Henry Jenkins, Lorenzo Vilches e Jesús Martín-Barbero, com contribuições em mídia e convergência; Eugênio Bucci e Omar Rincón, entre outros, com produções contemporâneas na área de TV pública. 
Normatizações e convencionalismo do telejornalismo não serviram de parâmetros para as pesquisas realizadas; novas diretrizes de avaliação precisaram ser traçadas para balizar as análises, pois a TV pública não suporta ou não deve suportar uma forma-conteúdo que possa ser impedimento para a informação de qualidade.

Mesmo em meio a um novo cenário de convergência das mídias tradicionais, todos os veículos dependem da audiência, emissoras comerciais ou públicas. Com o uso da internet ou não, a ética é bem vinda e necessária. Por isso, as perguntas a seguir são alçadas e refletidas no livro de forma implícita: a TV pública tem uma programação de efetivo interesse público? Valoriza, representa e se dirige a toda a diversidade brasileira? Possui estratégias de aproximação com o público, inclusive na linguagem? O público é um interlocutor presente em entrevistas e enunciados? A edição das matérias permite que a TV pública cumpra sua verdadeira função? Quais seriam as mudanças necessárias? Cada artigo pensa um destes temas, ou mais de um deles, conforme o programa televisivo analisado.

Em síntese, os textos cultivam um aspecto informativo e reflexivo, com constantes inquietações diante do objetivo da TV pública e do real cumprimento de seus objetivos explorando características, formatos e temas e dialogando com outras pesquisas afins.

A informação na TV pública é uma coletânea inovadora por pesquisar desiguais aspectos de programas telejornalísticos e informativos de emissora pública, que implicam em suscitar melhorias pontuais na atual programação.

O trabalho é, portanto, o resultado de pesquisas realizadas por quem estuda, conhece e interpreta a informação na TV de forma profunda e ampla. Por sua contemporaneidade e diversidade em torno de um mesmo tema, suplica a leitura completa de cada um dos artigos e premia o leitor com um conteúdo pronto para ser absorvido e citado como referência. 